\title{
The mechanism of pyrolysis of 9,9-dimethylfluorene
}

\author{
Hamish McNab \\ Department of Chemistry, The University of Edinburgh, \\ West Mains Road Edinburgh EH9 3JJ \\ E-mail: $\underline{H . M c N a b @ e d . a c . u k}$
}

For Charles Rees, on the occasion of his $75^{\text {th }}$ birthday

(received 15 Jun 02; accepted 27 Jul 02; published on the web 04 Aug 02)

\begin{abstract}
Flash vacuum pyrolysis (FVP) of 9,9-dimethylfluorene $\mathbf{7}$ and of the oxalates $\mathbf{1 5}$ and $\mathbf{1 6}$ at $800{ }^{\circ} \mathrm{C}$ (0.005 Torr) gives phenanthrene $\mathbf{8}$ and dibenzofulvene $\mathbf{1 3}$ as the major products. The phenanthrene $\mathbf{8}$ is shown to be formed by a free-radical ring expansion process from all three precursors. A radical mechanism also accounts for the formation of the fulvene $\mathbf{1 3}$ from the fluorene $\mathbf{7}$ and a small portion of the fulvene $\mathbf{1 3}$ from the oxalates $\mathbf{1 5}$ and $\mathbf{1 6 .}$
\end{abstract}

Keywords: Flash vacuum pyrolysis, radicals, ring expansions, eliminations

\section{Introduction}

Nearly 30 years ago, Brown and Butcher discovered an unexpected ring expansion of 3,3dimethyloxindole 1 to quinolin-2-one 2 under flash vacuum pyrolysis (FVP) conditions. ${ }^{1}$ We were intrigued by the mechanism of this process and designed ${ }^{13} \mathrm{C}$-labelling experiments which were consistent with the major ring expansion step being a neophyl-type free radical rearrangement after initial loss of a methyl group to give 2 (Scheme 1 , route a). ${ }^{2}$ The key intermediate in this rearrangement is the non-conjugated radical $\mathbf{3}$ which can attack either the benzene ring or the neighbouring carbonyl group; the results of labelling studies suggest that $c a$. $35 \%$ of the ring expansion pathway takes place by reaction at the carbonyl group. ${ }^{2}$ However, at the time, there was some doubt about the formally disallowed 1,2-hydrogen shift step ${ }^{2}(2 \rightarrow 3$ ) and some possible involvement of the exo-methylene indolinone $\mathbf{6}$, as originally proposed by Brown and Butcher, ${ }^{1}$ could not be unambiguously ruled out (Scheme 1, route b). Recently, authentic 6 has been made by an ester elimination method under FVP conditions; ${ }^{3}$ although no quinolinones were detected in this study it should be noted that the pyrolysis conditions required for the elimination are significantly milder than for the original ring expansion of $\mathbf{1}$. $^{1,3}$ On the 
other hand our original concerns regarding the 1,2-hydrogen shift may have been unfounded, since there are now many well authenticated cases of such migrations at high temperatures. ${ }^{4}$

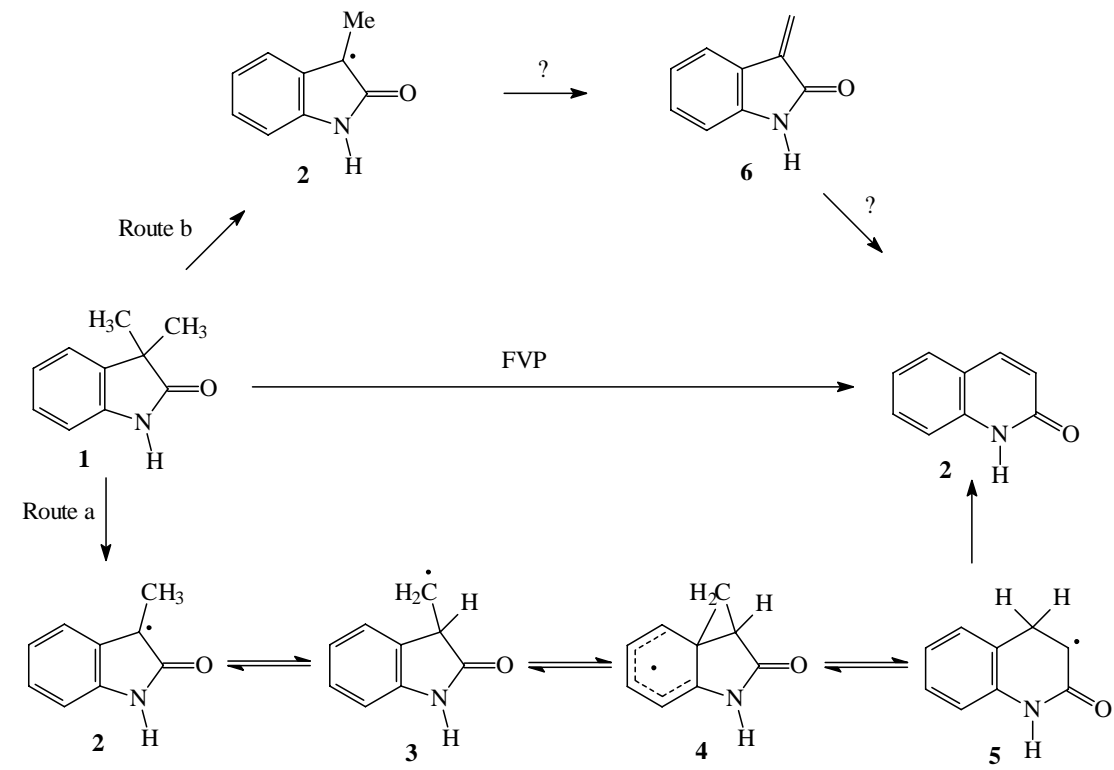

\section{Scheme 1}

Nevertheless, to provide final confirmation of the viability of the mechanism of Scheme 1, independent generation of the key radicals $\mathbf{2}$ and $\mathbf{3}$ are required but there are no obvious convenient routes to potential precursors of these species. We therefore required a model system in which the important facets of the process were maintained (gem-dimethyl group in the precursor, possibilities of $\mathrm{H}$-shift and neophyl rearrangement) but which allowed straightforward routes to analogues of 2, $\mathbf{3}$ and $\mathbf{6}$ and in addition removed the complication of competing reaction at the carbonyl group. The fluorene system met these objectives (Scheme 2). 9,9Dimethylfluorene 7 and the corresponding exo-methylene compound (dibenzofulvene 13) are well known and it should be possible to generate the radicals $\mathbf{9}$ and $\mathbf{1 0}$ independently by oxalate pyrolysis. Here we describe the results of these investigations.

\section{Results and Discussion}

9,9-Dimethylfluorene 7 was made in 65\% yield by treatment of fluorene with an excess of iodomethane under basic conditions in liquid ammonia. ${ }^{5}$ The acetate ${ }^{6} 14$ (46\% after purification), required as a source of authentic 13, and the oxalate 15 (76\%) were obtained by treatment of fluorene-9-methanol with acetyl chloride and oxalyl chloride, respectively, in ether solution in the presence of triethylamine. In order to obtain the isomeric oxalate 16, 9-hydroxy-9- 
methylfluorene 17 was first made by treatment of fluorenone with methyl magnesium iodide ${ }^{7}$ and the product was reacted with oxalyl chloride as above. In this case the yield of oxalate was low (34\%) under the standard conditions owing to steric hindrance; some starting material was also recovered.

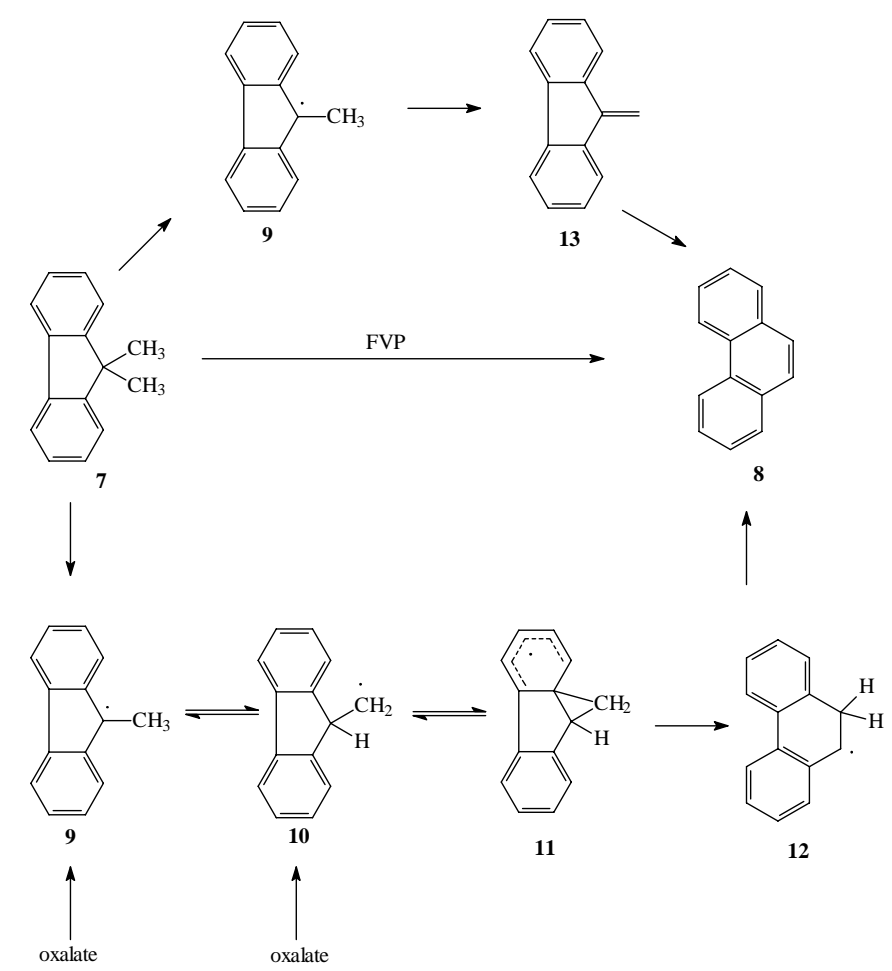

\section{Scheme 2}

FVP of 9,9-dimethylfluorene 7 at $800{ }^{\circ} \mathrm{C}$ gave a mixture of three main components analysed by GLC and GC-MS; no starting material remained at this temperature. The major products were phenanthrene 8 (43\%) and dibenzofulvene 13 (27\%) together with a trace (8\%) of fluorene 18 itself (dibenzofulvene:phenanthrene ratio 38:62, Table 1) (Scheme 3). The low level of fluorene detected may be an impurity in the starting material. The high level of exo-methylene product 13 was unexpected since the corresponding product was not obtained in the oxindole series but may reflect the thermodynamic stabilities of $\mathbf{6}$ and $\mathbf{1 3}$ relative to other species on their respective energy surfaces. 

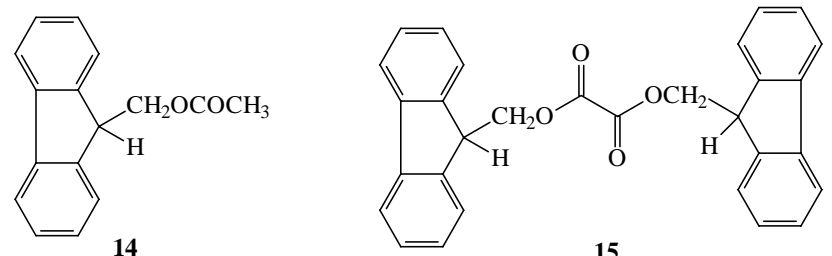

15
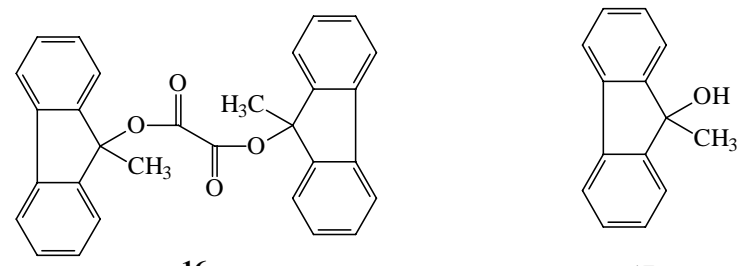

17

Since the two major products have one carbon atom less than the precursor it appears that, as with the dialkyloxindoles, homolysis of one $C$-methyl bond to give the stabilised fluorenyl radical 9 is the primary thermal process (Scheme 2). This can lead to the dibenzofulvene 13 by well-precedented $^{8} \beta$-cleavage of a hydrogen atom (Scheme 2). As shown in Scheme 2, there are two possible routes to the phenanthrene, either via the neophyl rearrangement route involving 9 and $\mathbf{1 0}$ or by direct ring expansion of dibenzofulvene 13. It is important to define the level of any rearrangement of $\mathbf{1 3}$ to $\mathbf{8}$ under the conditions of the pyrolysis. This process is $\mathrm{known}^{9}$ but apparently takes place under more vigorous conditions (flow pyrolysis at $>800{ }^{\circ} \mathrm{C}$ ) than should be obtained in our experiments.

Table 1. Ratios of dibenzofulvene $\mathbf{1 3}$ to phenanthrene $\mathbf{8}$ obtained from pyrolysis of different precursors

\begin{tabular}{cc}
\hline Precursor & Dibenzofulvene:phenanthreneratio \\
\hline $\mathbf{7}$ & $38: 62$ \\
$\mathbf{1 4}$ & $97: 3$ \\
$\mathbf{1 5}$ & $78: 22$ \\
$\mathbf{1 6}$ & $83: 17$ \\
\hline
\end{tabular}

Accordingly, a control pyrolysis of the acetate 14 was carried out under similar conditions to those of 7 (furnace temperature $800{ }^{\circ} \mathrm{C}$ ). Acetate pyrolysis is known to take place by a concerted cis-elimination mechanism ${ }^{10}$ to give alkenes, so the maximum amount of any ring expansion of dibenzofulvene 13 could therefore be determined. This experiment provided a $43 \%$ yield of dibenzofulvene $\mathbf{1 3}$ together with just 1.3\% of phenanthrene $\mathbf{8}$ (dibenzofulvene:phenanthrene ratio 97:3, Table 1) and a trace of fluorene 18. Hence the maximum amount of direct ring expansion of dibenzofulvene $\mathbf{1 3}$ at $800{ }^{\circ} \mathrm{C}$ is just $3 \%$ under our conditions, which suggests that the vast majority of the phenanthrene from 7 must arise by the radical mechanism. It follows that the 9- 
methylfluorenyl radical 9 can proceed directly to products either by ring expansion or by $\beta$ cleavage and that these processes occur in $60: 40$ ratio at $800{ }^{\circ} \mathrm{C}$.
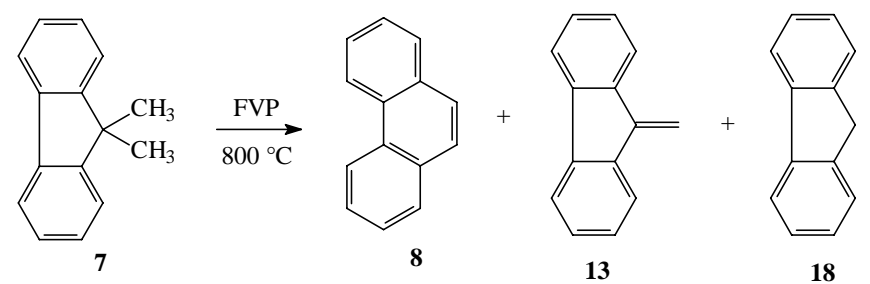

\section{Scheme 3}

The small amount of fluorene 18 (2\%) obtained from the pyrolysis of the acetate $\mathbf{1 4}$ may be due to hydrogen atom capture after competitive free radical cleavage of the $\mathrm{CH}-\mathrm{CH}_{2}$ bond.

In order to provide final confirmation of the mechanism, the oxalates $\mathbf{1 6}$ and $\mathbf{1 5}$ were pyrolysed at $800{ }^{\circ} \mathrm{C}$ to provide 'authentic' sources of the key radical intermediates $\mathbf{9}$ and $\mathbf{1 0}$. Although oxalates are excellent sources of unsubstituted benzyl radicals under FVP conditions, they can also undergo competitive ester-type eliminations when the benzyl group is substituted. Thus Trahanovsky and co-workers report that di- $\alpha$-methylbenzyl oxalate $\mathbf{1 9}$ gives styrene $\mathbf{2 0}$ and 2,3-diphenylbutanes 21 in ratios ranging from 83:17 to 90:10 (Scheme 4). ${ }^{11}$ Whereas the diphenylbutanes $\mathbf{2 1}$ can arise only by coupling of the $\alpha$-methylbenzyl radicals 22 , the styrene $\mathbf{2 0}$ could be formed either by ester-type elimination directly from the oxalate or by loss of a hydrogen atom from the $\alpha$-methylbenzyl radicals 22 (Scheme 4). ${ }^{11}$ The latter route was not thought to be important since at the time it was expected that the styrene would arise by disproportionation which should also provide ethylbenzene and this product was not observed in any significant amount. ${ }^{11}$ However, in our case, 9-methylfluorene was absent in the pyrolysis of $\mathbf{7}$ yet considerable amounts of dibenzofulvene $\mathbf{1 3}$ were obtained, so it is clear that the alkene must arise by radical fragmentation rather than disproportionation.

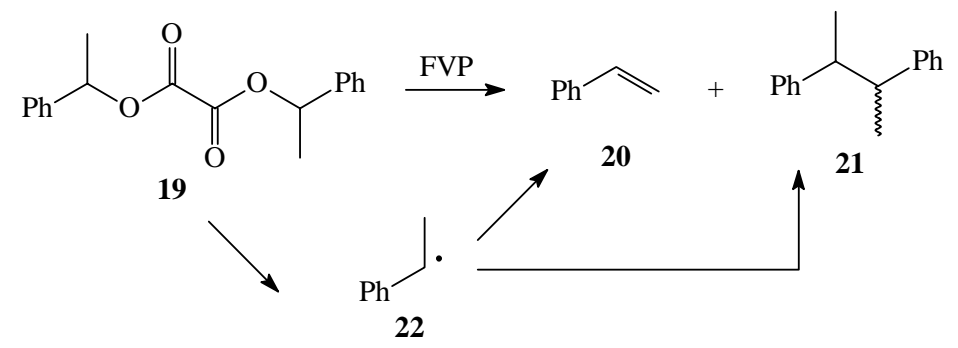

\section{Scheme 4}

FVP of the oxalates $\mathbf{1 5}$ and $\mathbf{1 6}$ at $800{ }^{\circ} \mathrm{C}$ gave dibenzofulvene $\mathbf{1 3}$ and phenanthrene $\mathbf{8}$ in ratios of 78:22 and 83:17 respectively (Table 1). These figures, measured by NMR integrals, are 
not significantly different from one another and are very close to the range observed by Trahanovsky ${ }^{11}$ for the elimination:radical coupling ratio. Because very much more phenanthrene $\mathbf{8}$ is found than in the control pyrolysis of 14, it suggests that the radicals $\mathbf{9}$ and $\mathbf{1 0}$ have been successfully generated and that they both proceed to phenanthrene $\mathbf{8}$ - supporting the mechanism of Scheme 2. In addition, the analysis of products from 7 now suggests that the population of radical 9 partitions itself between ring expansion to phenanthrene 8 (60\% of pathway) and scission to dibenzofulvene $\mathbf{1 3}$ (40\% of pathway) and therefore that this must also be a viable pathway for the oxalate-derived radicals. Thus, in pyrolyses of the oxalate $\mathbf{1 6}$ dibenzofulvene $\mathbf{1 3}$ should be generated from 9 to the extent of $40 / 60$ of the 17\% of phenanthrene 8 (i.e. ca. 11\%) and the cis-elimination accounts for the remaining $89 \%$ of this product. This duality of mechanism is likely also to be followed in the formation of styrene from di- $\alpha$-methylbenzyl oxalate 19.

In conclusion, the homolysis-rearrangement mechanism previously discovered in the indole series has been shown to apply also to hydrocarbon ring expansion. However, the level of competing alkene product is much higher in the current example, which will limit the utility of the ring expansion process in synthesis. The results also suggest that oxalate pyrolyses may give rise to alkene products by two distinct mechanisms, viz. concerted cis-elimination and by loss of a hydrogen atom from the radical, though the former accounts for $c a .90 \%$ of the productforming pathway.

\section{Experimental Section}

General Procedures. ${ }^{1} \mathrm{H}$ and ${ }^{13} \mathrm{C}$ NMR spectra were recorded at 200 and $50 \mathrm{MHz}$ respectively for solutions in $\left[{ }^{2} \mathrm{H}\right]$ chloroform. ${ }^{13} \mathrm{C}$ NMR signals are due to $\mathrm{CH}$ resonances unless otherwise stated. Mass spectra were obtained under electron impact (EI) ionisation conditions unless otherwise stated.

9,9-Dimethylfluorene (7). Sodium (1.27 g, $55 \mathrm{mmol}$ ) was added in small pieces with stirring to liquid ammonia $\left(100 \mathrm{~cm}^{3}\right)$ containing a trace of iron(III) nitrate. When the colour was discharged, a solution of fluorene $18(4.2 \mathrm{~g}, 25 \mathrm{mmol})$ in ether $\left(50 \mathrm{~cm}^{3}\right)$ was added and the mixture was stirred for $2 \mathrm{~h}$. A solution of iodomethane $(10 \mathrm{~g}, 70 \mathrm{mmol})$ in ether $\left(10 \mathrm{~cm}^{3}\right)$ was then added and after stirring for a further $2 \mathrm{~h}$ the ammonia was allowed to evaporate overnight. Water $\left(20 \mathrm{~cm}^{3}\right)$ was added and the suspension was acidified with dilute hydrochloric acid. The organic layer was separated, the aqueous layer was extracted once with ether, the combined organic extracts were dried $\left(\mathrm{Na}_{2} \mathrm{SO}_{4}\right)$ and concentrated to leave 9,9-dimethylfluorene 7 as colourless crystals $(3.17 \mathrm{~g}, 65 \%)$ after recrystallisation from ethanol, $\delta_{\mathrm{H}} 7.70-7.82(2 \mathrm{H}, \mathrm{m}), 7.28-$ $7.47(6 \mathrm{H}, \mathrm{m})$ and $1.53(6 \mathrm{H}, \mathrm{s}) ; \delta_{\mathrm{C}} 153.51$ (quat), 139.10 (quat), 127.08, 126.79, 122.42, 119.83, 46.69 (quat) and $27.01\left(\mathrm{CH}_{3}\right)$. 
9-Hydroxy-9-methylfluorene (17). Compound 17 was obtained in $61 \%$ yield by the literature $\operatorname{method}^{7}$ after recrystallisation from ethanol, $\delta_{\mathrm{H}} 7.5-7.7(4 \mathrm{H}, \mathrm{m}), 7.28-7.44(4 \mathrm{H}, \mathrm{m}), 1.82(1 \mathrm{H}$, br. s) and $1.73(3 \mathrm{H}, \mathrm{s})$.

\section{General method for the preparation of oxalates 15 and 16}

A solution of the alcohol $(0.39 \mathrm{~g}, 2 \mathrm{mmol})$ and triethylamine $(0.30 \mathrm{~g}, 3 \mathrm{mmol})$ in ether $\left(20 \mathrm{~cm}^{3}\right)$ was cooled to $0{ }^{\circ} \mathrm{C}$ and treated dropwise with a solution of oxalyl chloride $(0.13 \mathrm{~g}, 1 \mathrm{mmol})$ in ether $\left(2 \mathrm{~cm}^{3}\right)$. The mixture was stirred for $10 \mathrm{~min}$, filtered, and the solid residue was washed with water to give the oxalate ester as a colourless solid. The following products were made in this way.

Di-(fluoren-9-ylmethyl) oxalate (15). (0.34 g, 76\%) (from 9-hydroxymethylfluorene) mp 174$176{ }^{\circ} \mathrm{C}$ (from dimethyl formamide) (Found: $\mathrm{C}, 80.6 ; \mathrm{H}, 4.95 . \mathrm{C}_{30} \mathrm{H}_{22} \mathrm{O}_{4}$ requires $\mathrm{C}, 80.7 ; \mathrm{H}$, 4.95\%) $\delta_{\mathrm{H}} 7.78\left(4 \mathrm{H}, \mathrm{d},{ }^{3} J 7.1\right), 7.65\left(4 \mathrm{H}, \mathrm{d},{ }^{3} J 7.3\right), 7.43(4 \mathrm{H}, \mathrm{t}), 7.32(4 \mathrm{H}, \mathrm{t}), 4.59\left(4 \mathrm{H}, \mathrm{d},{ }^{3} J 7.4\right)$ and 4.33 (2H, t, ${ }^{3} J$ 7.4); $\delta_{\mathrm{C}} 157.45$ (quat), 142.91 (quat), 141.29 (quat), 128.02, 127.27, 125.07, 120.08, $68.78\left(\mathrm{CH}_{2}\right)$ and 46.36; $\mathrm{m} / \mathrm{z} 446\left(\mathrm{M}^{+}, 1 \%\right), 198(100)$ and $178(26)$.

Di-(9-methylfluoren-9-yl) oxalate (16). (0.15 g, 34\%), (from 9-hydroxy-9-methylfluorene 17), recrystallised from dimethyl formamide [Found: $\mathrm{C}, 80.4 ; \mathrm{H}, 5.05 ; \mathrm{N}, 0.35 . \mathrm{C}_{30} \mathrm{H}_{22} \mathrm{O}_{4} \cdot(0.1 \mathrm{DMF})$ requires C, 80.2; H, 5.0; N, 0.3\%] (sample could not be freed from traces of DMF) $\delta_{\mathrm{H}} 7.64(4 \mathrm{H}$, d, ${ }^{3} J$ 7.6), 7.45 (4H, d, ${ }^{3} J$ 7.2), 7.25-7.38 (8H, m), and $1.83(3 \mathrm{H}, \mathrm{s}) ; \delta_{\mathrm{C}} 155.17$ (quat), 144.87 (quat), 139.64 (quat), 129.25, 127.86, 123.05, 119.61, 120.08, 45.82 (quat) and $25.07\left(\mathrm{CH}_{3}\right)$. Some alcohol starting material 17 was also recovered from this reaction.

9-Acetoxymethylfluorene (14). A solution of 9-hydroxymethylfluorene 17 (0.39 g, 2 mmol) and triethylamine $(0.30 \mathrm{~g}, 3 \mathrm{mmol})$ in ether $\left(20 \mathrm{~cm}^{3}\right)$ was cooled to $0{ }^{\circ} \mathrm{C}$ and treated dropwise with a solution of acetyl chloride $(0.16 \mathrm{~g}, 2 \mathrm{mmol})$ in ether $\left(2 \mathrm{~cm}^{3}\right)$. The mixture was stirred for $30 \mathrm{~min}$ at $0{ }^{\circ} \mathrm{C}$ and a further $30 \mathrm{~min}$ at room temperature, filtered, and the solid residue was washed with water. The organic portion of the filtrate was dried $\left(\mathrm{Na}_{2} \mathrm{SO}_{4}\right)$ and concentrated to give an oil which slowly crystallised $(0.51 \mathrm{~g})$. Recrystallisation from ethyl acetate gave 9acetoxymethylfluorene 14, (0.22 g, 46\%) mp 77-79 ${ }^{\circ} \mathrm{C}$ (lit., $\left.{ }^{6} 82-83{ }^{\circ} \mathrm{C}\right), \delta_{\mathrm{H}} 7.77\left(2 \mathrm{H}, \mathrm{d},{ }^{3} \mathrm{~J} 7.3\right)$, 7.60 (2H, d, ${ }^{3} J$ 7.2), 7.27-7.45 (4H, m), 4.37 (2H, d, ${ }^{3} J$ 6.9), 4.21 (1H, t, $\left.{ }^{3} J 6.9\right)$ and 2.15 (3H, s); $\delta_{\mathrm{C}} 170.69$ (quat), 143.69 (quat), 141.16 (quat), 127.60, 126.90, 124.83, 119.84, 120.08, 66.24 $\left(\mathrm{CH}_{2}\right), 46.65$ and $20.74\left(\mathrm{CH}_{3}\right)$.

\section{Flash vacuum pyrolysis experiments}

The precursor was volatilised under vacuum through an empty, electrically heated silica tube (35 $\times 2.5 \mathrm{~cm}$ ) and the products were collected in a liquid nitrogen trap situated at the exit point of the furnace. The precursor, pyrolysis conditions [quantity of precursor, furnace temperature $\left(T_{\mathrm{f}}\right)$, inlet temperature $\left(T_{\mathrm{i}}\right)$, pressure range $(P)$ and pyrolysis time $\left.(t)\right]$ and products are given. The entire pyrolysate was dissolved in $\mathrm{CDCl}_{3}$ and analysed by GLC (packed column, 5\% SE30, $200{ }^{\circ} \mathrm{C}$ ) and by ${ }^{1} \mathrm{H}$ NMR spectroscopy. The three products which eluted from the GLC were 
identified as fluorene 18, dibenzofulvene $\mathbf{1 3}$ and phenanthrene $\mathbf{8}$ respectively by comparison of retention times with authentic standards and the conclusions were supported by GC-MS analysis. Yields were calculated from the NMR spectrum of the crude pyrolysates using cyclohexane $(5 \mu \mathrm{l})$ as internal standard; the following characteristic resonances were used in the analysis: fluorene $^{12} 18 \delta_{\mathrm{H}} 3.93(2 \mathrm{H}, \mathrm{s})$; dibenzofulvene ${ }^{6} 13 \delta_{\mathrm{H}} 6.10(2 \mathrm{H}, \mathrm{s})$; phenanthrene ${ }^{12} 8 \delta_{\mathrm{H}} 8.75$ (2H, $\mathrm{m})$.

9,9-Dimethylfluorene (7). (0.059 g, $0.30 \mathrm{mmol})\left(T_{\mathrm{f}} 800{ }^{\circ} \mathrm{C}, T_{\mathrm{i}} 8{ }^{\circ} \mathrm{C}, P\right.$ 0.005-0.02 Torr, $t 20$ $\min )$ gave fluorene 18 (8\%), dibenzofulvene 13 (27\%) and phenanthrene 8 (43\%).

9-Acetoxymethylfluorene (14). (0.045 g, $0.19 \mathrm{mmol})\left(T_{\mathrm{f}} 800{ }^{\circ} \mathrm{C}, T_{\mathrm{i}} 80{ }^{\circ} \mathrm{C}, P 0.005\right.$ Torr, $t 40$ min) gave fluorene 18 (2\%), dibenzofulvene 13 (43\%) and phenanthrene 8 (1.3\%).

Di-(fluoren-9-ylmethyl) oxalate (15). (0.057 g, $0.13 \mathrm{mmol})\left(T_{\mathrm{f}} 800{ }^{\circ} \mathrm{C}, T_{\mathrm{i}} 210{ }^{\circ} \mathrm{C}, P 0.005\right.$ Torr, t $30 \mathrm{~min}$ ) gave fluorene 18 (7\%), dibenzofulvene 13 (53\%) and phenanthrene 8 (15\%).

Di-(9-methylfluoren-9-yl) oxalate (16). (0.055 g, $0.13 \mathrm{mmol})\left(T_{\mathrm{f}} 800{ }^{\circ} \mathrm{C}, T_{\mathrm{i}} 180{ }^{\circ} \mathrm{C}, P 0.005\right.$ Torr, $t 10 \mathrm{~min}$ ) gave dibenzofulvene 13 (45\%) and phenanthrene 8 (9\%) (fluorene was absent).

\section{Acknowledgements}

I am grateful to Professor R.F.C. Brown for helpful discussions.

\section{References}

1. Brown, R.F.C.; Butcher, M. Aust. J. Chem. 1973, 26, 369.

2. McNab, H. J. Chem. Soc., Chem. Commun. 1990, 543.

3. Bell, S.E.V.; Brown, R.F.C.; Eastwood, F.W.; Horvath, J. M. Aust. J. Chem. 2000, 53, 183.

4. For example, Brooks, M.A.; Scott, L.T. J. Am. Chem. Soc. 1999, 121, 5444.

5. $\quad c f$. Gautier, J.A.; Miocque, M.; Moskowitz, H. J. Organometallic Chem. 1963, 1, 212.

6. Neuenschwander, M.; Vögeli, R.; Fahrni, H.-P.; Lehmann, H.; Ruder, J.-P. Helv. Chim. Acta 1977, 60, 1073.

7. Ullmann, F.; von Wurstemberger, R. Ber. Dtsch. Chem. Ges. 1905, 38, 4105.

8. For example, Cadogan, J.I.G.; Hickson, C.L.; McNab, H. Tetrahedron 1986, 42, 2136.

9. Hofmann, J.; Zimmermann, G.; Guthier, K.; Hebgen, P.; Homann, K-H. Liebigs Ann. Chem. 1995, 631.

10. DePuy, C.H.; King, R.W. Chem. Rev. 1960, 60, 431.

11. Trahanovsky, W.S.; Ong, C.C.; Pataky, J.G.; Weitl, F.L.; Mullen, P.W.; Clardy, J.C.; Hansen, R.S. J. Org. Chem. 1971, 36, 3575.

12. Pouchert, J.; Behnke, J. The Aldrich Library of ${ }^{13} \mathrm{C}$ and ${ }^{1} \mathrm{H}$ FTNMR Spectra, Aldrich Chemical Company Inc., Milwaukee, 1993. 